\title{
Evaluasi Implementasi Kebijakan Standar Pelayanan Minimal Unit Radiologi Rumah Sakit Umum Daerah (RSUD) Dr. Rasidin Padang
}

Tosi Rahmaddian ${ }^{1}$, Rima Semiarty ${ }^{2}$, Ratni Prima Lita ${ }^{2}$

\begin{abstract}
Abstrak
Pelayanan radiologi di rumah sakit sangat penting sebagai bagian yang terintegrasi dari pelayanan kesehatan secara menyeluruh. Tujuan: Mengevaluasi implementasi Kebijakan Standar Pelayanan Minimal (SPM) unit radiologi di RSUD X Padang. Metode: Penelitian ini menggunakan metode kualitatif melalui wawancara mendalam, Focus Group Discussion, telaah dokumen dan observasi. Pengumpulan data dilakukan dengan cara wawancara mendalam kepada delapan orang informan dan Focus Group Discussion kepada enam orang informan. Komponen yang diteliti mengenai input (kebijakan, sumber daya), process (komunikasi, disposisi/ sikap, struktur birokrasi), output (pencapaian indikator SPM). Hasil: penelitian menunjukan bahwa kebijakan tersedia, namun sumber daya belum lengkap. Komunikasi tidak berjalan dengan baik. Disposisi/ sikap dalam hal ini terkendala oleh dokter yang tidak standby. Struktur birokrasi berjalan sesuai dengan prosedur. Tiga target indikator SPM unit radiologi belum tercapai, yaitu; waktu tunggu hasil pelayanan thorax foto, kejadian kegagalan foto rontgen, dan kepuasan pelanggan. Simpulan: implementasi kebijakan standar pelayanan minimal unit radiologi RSUD X Padang tidak berjalan maksimal dan hasil belum mencapai target.

Kata kunci: standar pelayanan minimal, unit radiologi, kualitatif
\end{abstract}

\section{Abstract}

The radiology services in hospitals as an integrated part of complete health services. Objectives: To evaluated the implementation of the Minimum Service Standard Policy (MSS) of the radiology unit at the RSUD X Padang. Methods: This study used qualitative methods through in-depth interviews, Focus Group Discussions, document review and observation. Data collection is done by interviewing the informant group, and Focus Group Discussion for six informants. Components that discuss input (policies, resources), processes (communication, disposition / attitude, bureaucratic structure), output (achievement of MSS indicators). Results: This study indicated that policies were available, but resources were not complete yet. Communication did not work well. Disposition/attitude in this case was constrained by doctors who are not on standby. The bureaucratic structure underwent according to the procedure. The achievement of three targets of the MSS radiology unit indicator, waiting for the time to wait for the results of the chest $X$-ray service, incident $X$-ray photo failure and customer satisfaction. Conclusion: the application of a minimum service standard for the radiology unit at the RSUD X Padang did not run optimally and the results had not reached the target yet.

Keywords: minimum service standards, radiology unit, qualitative

Affiliasi penulis: 1. Prodi Magister Kesehatan Masyarakat Fakultas Kedokteran Universitas Andalas Padang (FK Unand), 2. Bagian IImu Kesehatan Masyarakat Fakultas Kedokteran Universitas Andalas Korespondensi Rima Semiarty,

Email: rimasemiarty@med.unand.ac.id, Telp: 082287663448

\section{PENDAHULUAN}

Radiologi merupakan sarana pemeriksaan penunjang untuk menegakkan diagnosis penyakit dan pemberian terapi yang cepat dan tepat bagi pasien yang menjadikan pelayanan radiologi telah diselenggarakan di berbagai sarana pelayanan 
kesehatan seperti puskesmas, klinik swasta dan rumah sakit di seluruh indonesia. ${ }^{1} \quad$ Pelayanan unit radiologi yang diberikan kepada pasien rumah sakit harus sesuai dengan standar mutu. Pelayanan yang memenuhi standar akan memberikan hasil yang terbaik dan akan lebih terarah dalam pelaksanaannya. $^{2}$

Mutu merupakan suatu kepatuhan terhadap standar yang telah ditetapkan atau sesuai dengan persyaratan. Unit radiologi sebagai sarana penunjang dalam menegakkan diagnosis harus dapat memenuhi standar pelayanan minimal rumah sakit. ${ }^{3}$ Standar Pelayanan Minimal (SPM) adalah ketentuan tentang jenis dan mutu pelayanan dasar yang merupakan urusan wajib daerah yang berhak diperoleh setiap warga secara minimal. Standar Pelayanan Minimal (SPM) rumah sakit dalam pedoman ini meliputi jenis pelayanan, indikator dan standar pencapaian kinerja pelayanan rumah sakit. ${ }^{4}$

Standar Pelayanan Minimal (SPM) unit radiologi RSUD $X$ telah ditetapkan melalui Peraturan Walikota Padang nomor 39 tahun 2014 yang dimaksudkan sebagai panduan bagi rumah sakit dalam melaksanakan perencanaan, pelaksanaan, pengendalian, pengawasan, dan pertanggungjawaban penyelenggaraan pelayanan di unit radiologi dengan tujuan meningkatkan dan menjamin mutu pelayanan kepada masyarakat. ${ }^{5}$ Sedangkan, SPM unit radiologi RSUD $X$ belum memenuhi capaian target dalam indikator SPM yang merupakan tolak ukur dalam penilaian kinerja RSUD itu sendiri. Indikator SPM yang dipakai di unit radiologi adalah waktu tunggu foto thorax yang tidak lebih dari tiga jam, pelaksana ekspertis adalah dokter spesialis radiologi, Kerusakan kegagalan pelayanan rontgen berupa kerusakan foto $\leq$ $2 \%$, kepuasan pelanggan ditetapkan $\geq 80 \%{ }^{5}$

Keberhasilan implementasi kebijakan suatu pelayanan akan ditentukan oleh beberapa variabel yaitu komunikasi, sumber daya, disposisi/ sikap dan struktur birokrasi. ${ }^{6}$

\section{METODE}

Penelitian ini menggunakan metode kualitatif dengan desain deskriptif yang bertujuan memberikan gambaran secara cermat tentang evaluasi implementasi kebijakan Standar Pelayanan Minimal
(SPM) pada unit radiologi RSUD X Padang. Penelitian ini dilakukan di unit radiologi RSUD $X$ Padang pada bulan April 2018 sampai dengan September 2018.

Informasi pada metode kualitatif ini didapatkan dengan melakukan wawancara mendalam (indept interview), FGD (Focus Group Discussion), telaah dokumen dan observasi. Informan wawancara mendalam (indept interview) diantaranya, direktur RSUD X Padang, kepala bidang pelayanan medis dan penunjang medis, kepala unit ruangan radiologi, ketua komite mutu, dan dokter spesialis radiologi, serta staf radiologi sebagai pelaksana pelayanan. Informan untuk FGD (Focus Group Discussion) pada penelitian ini diantaranya yaitu 6 (enam) orang pasien radiologi.

Alat yang digunakan dalam penelitian ini adalah pedoman wawancara, pedoman FGD, lembar observasi, telaah dokumen, tape recorder dan kamera.

\section{HASIL}

\section{Komponen Input}

a. Kebijakan

Penjelasan melalui wawancara mendalam, telaah dokumen dan observasi bahwa kebijakan pelaksanaan pengukuran SPM berdasarkan surat edaran Menteri Kesehatan Republik Indonesia nomor 129 tahun 2008 tentang Standar Pelayanan Minimal Rumah Sakit. ${ }^{4}$ Pada tingkat daerah telah diatur secara khusus kebijakan pelaksanaan SPM RSUD X Padang berdasarkan Peraturan Walikota Padang nomor 39 tahun 2014 tentang Standar Pelayanan Minimal RSUD X Padang. ${ }^{5}$

\section{b. Sumber daya}

Penjelasan melalui wawancara mendalam, telaah dokumen dan observasi bahwa jumlah ketenagaan unit radiologi belum dapat memenuhi persyaratan yang telah diatur dalam Keputusan Menteri Kesehatan nomor 1014 tahun 2008 dan dokter spesialis radiologi yang masih referal membuat pelayanan unit radiologi jadi tidak optimal dikarenakan kebutuhan pasien terhadap pelayanan yang cepat dan tepat sangat penting bagi rumah sakit untuk memberikan pelayanan terbaik. ${ }^{7}$

Berkaitan dengan Rencana Kerja Perubahan Anggaran (RKPA) dan Rencana strategi (Renstra), RSUD X seharusnya telah menyediakan peralatan 
berupa satu unit CT Scan sebagai penunjang diagnosa penyakit pasien, namun sampai saat ini belum terealisasi dikarenakan Laporan Tahunan RSUD X Padang tahun 2017 tentang pengadaan alat kesehatan DAK (Dana Alokasi Khusus) RSUD mengalami hambatan disebabkan karena keterlambatan administrasi. ${ }^{8}$

\section{Komponen Proces}

a. Komunikasi

Penjelasan melalui wawancara mendalam, FGD dan observasi bahwa tidak dilakukan sosialisasi tentang standar yang harus diketahui dalam pelayanan radiologi. Standar yang berlaku dalam pelayanan hanya ada didalam buku SPM yang juga tidak diketahui oleh semua petugas. Pimpinan rumah sakit yang menyatakan butuh waktu lama dalam mensosilisasikan SPM menunjukkan bahwa rendahnya kesadaran pimpinan dalam menjalankan pelayanan, setiap petugas harus mengetahui dan memahami standar yang berlaku. Hal ini merupakan kegagalan pimpinan dalam menerapkan kebijakan SPM, sehingga tujuan pencapaian target indikator SPM tidak berjalan dengan baik.

Pedoman pelayanan unit radiologi belum tersedia, berdasarkan SOP merupakan salah satu kendala bagi manajemen RSUD dalam upaya tercapainya target pada indikator-indikator kebijakan SPM.

\section{b. Disposisi/ Sikap}

Penjelasan melalui wawancara mendalam, FGD dan observasi bahwa petugas memiliki sikap yang mau memberikan pelayanan yang baik yang sesuai dengan SPM dengan pertimbangan membantu rumah sakit untuk memberikan pelayanan terbaik, namun terdapat beberapa kendala yang dihadapi, diantaranya dikarenakan pelaksana ekspertisi (dokter spesialis radiologi) hanya terjadwal hadir di RSUD pada hari Senin dan Kamis sehingga pelayanan tidak berjalan secara optimal.

Pemahaman, tenaga, ketersediaan fasilitas, keinginan dan kemauan pelaksana yang masih kurang dalam menjalankan tugas agar sesuai dengan aturan menjadi salah satu kendala lainnya bagi pelaksana RSUD dalam melaksanakan pelayanan yang sesuai dengan SPM.

\section{c. Struktur Birokrasi \\ Penjelasan melalaui wawancara mendalam,} telaah dokumen dan observasi bahwa pelaksanaan tanggung jawab Standar Pelayanan Minimal (SPM) yang diserahkan kepada ketua komite mutu merupakan bagian dari struktur organisasi yang harus diemban dan dilaksanakan sebaik-baiknya. Adanya anggaran, fasilitas, dan telah dilaksanakannya suatu koordinasi dengan pihak ketiga untuk menjalankan tugas pelaksanaan pengukuran SPM khususnya unit radiologi merupakan bentuk dari telah dijalankan tugas dan tanggung jawab yang diberikan kepada ketua komite mutu.

\section{Komponen Output}

Interpretasi foto thorak membutuhkan waktu tiga hari untuk mendapatkan hasil ekspertisi dari dokter spesialis radiologi, hal ini dikarenakan radiolog merupakan dokter yang masih bersifat referal (tidak tetap) yang jam kerjanya terjadwal pada hari Selasa dan Kamis, sehingga pasien harus menunggu lebih lama untuk memperoleh foto hasil rontgen.

Dokter spesialis radiologi yang bertanggung jawab sebagai pelaksana ekspertisi unit radiologi telah sesuai dengan ketentuan yang ditetapkan pada Standar Pelayanan Minimal (SPM) unit radiologi, yaitu $100 \%$ dokter spesialis radiologi.

Kerusakan foto rontgen yang targetnya tidak tercapai merupakan salah satu gambaran dari kurangnya efektifitas dan efisiensi dari petugas dalam melaksanakan pelayanan rontgen.

Kepuasan pasien yang hanya $62 \%$ terhadap pelayanan unit radiologi menjelaskan bahwa pelaksana program perlu untuk meningkatkan kinerja dan memberi pelayanan terbaik kepada pasien sehingga dapat memberikan kenyamanan bagi pasien pada saat merujuk ke unit radiologi. 


\section{PEMBAHASAN}

\section{Komponen Input}

a. Kebijakan

Pemerintah pusat telah membuat kebijakan terkait pelayanan yang harus dijalankan sesuai dengan standar, yaitu berdasarkan surat edaran Menteri Kesehatan Republik Indonesia nomor 129 tahun 2008 tentang Standar Pelayanan Minimal Rumah Sakit. ${ }^{4}$ Pada tingkat daerah telah diatur secara khusus kebijakan pelaksanaan SPM RSUD X Padang berdasarkan Peraturan Walikota Padang nomor 39 tahun 2014 tentang Standar Pelayanan Minimal RSUD $X$ Padang. ${ }^{5}$ Peraturan tersebut telah menjelaskan secara rinci aturan teknis dan target yang harus dicapai oleh unit radiologi, diantaranya waktu tunggu hasil pelayanan foto torak, pelaksana ekspertisi hasil pemeriksaan rontgen, kejadian kegagalan pelayanan rontgen dan kepuasan pelanggan. Hasil laporan evaluasi SPM menunjukan masih belum tercapainya tiga dari empat target dalam indikator-indikator SPM unit radiologi.

Peraturan Walikota Padang nomor 39 tahun 2014 tentang SPM, menjelaskan bahwa Standar Pelayanan Minimal (SPM) merupakan acuan bagi rumah sakit dalam melaksanakan perencanaan, pelaksanaan, pengendalian, pengawasan dan pertanggungjawaban penyelenggaraan pelayanan di rumah sakit. Pelaksanaan pelayanan yang sesuai dengan SPM bertujuan untuk meningkatkan dan menjamin mutu pelayanan rumah sakit kepada masyarakat. ${ }^{5}$

Suatu kebijakan yang diimplementasikan oleh pengambil keputusan dan pemegang program kesehatan harus berjalan sesuai dengan prosedur dan target yang telah ditetapkan, perlu adanya komitmen bagi para pemegang dan pelaksana kebijakan sehingga kebijakan yang ada telah dijalankan atau dilaksanakan secara terus-menerus.

\section{b. Sumber Daya}

Jumlah ketenagaan unit radiologi belum dapat memenuhi persyaratan yang telah diatur dalam Keputusan Menteri Kesehatan nomor 1014 tahun 2008, dan dokter spesialis radiologi yang masih referal membuat pelayanan unit radiologi jadi tidak optimal dikarenakan kebutuhan pasien terhadap pelayanan yang cepat dan tepat sangat penting bagi rumah sakit untuk memberikan pelayanan terbaik. ${ }^{7}$

Berdasarkan Rencana Kerja Perubahan Anggaran (RKPA) dan Rencana strategi (Renstra), RSUD X Padang seharusnya telah menyediakan peralatan berupa satu unit CT Scan sebagai penunjang diagnosa penyakit pasien, namun sampai saat ini belum terealisasi dikarenakan berdasarkan Laporan Tahunan RSUD X Padang tahun 2017 bahwa pengadaan alat kesehatan DAK (Dana Alokasi Khusus) RSUD mengalami hambatan disebabkan karena keterlambatan administrasi. ${ }^{8}$

Upaya peningkatan mutu rumah sakit sudah seharusnya pihak manajemen RSUD memenuhi segala kebutuhan fasilitas yang telah dianggarkan untuk memaksimalkan kinerja unit radiologi, serta melengkapi akses informasi bagi pasien dalam melakukan rujukan ke unit radiologi.

Sejalan dengan penelitian yang dilakukan oleh Kuzairi (2017) menyatakan bahwa kurangnya SDM terlatih pada unit radiologi seperti dokter spesialis radiologi mengakibatkan pencapaian indikator SPM rumah sakit dipelayanan radiologi menjadi rendah. ${ }^{9}$ Hasil penelitian Saputra (2014) menjelaskan bahwa dengan tercukupinya kebutuhan tenaga dan fasilitas rumah sakit, tentu akan dapat menunjang kinerja rumah sakit itu sendiri. ${ }^{10}$

Komunikasi kebijakan kepada pelaksana kebijakan dan seberapapun perintah dan kewenangan yang telah diberikan, tetapi apabila sumber daya yang tersedia tidak mendukung dalam proses pelaksanaan kegiatan organisasi maka hal ini dapat menghambat pelaksana kebijakan. ${ }^{11}$

\section{Komponen Process}

a. Komunikasi

Berdasarkan hasil penelitian menunjukkan bahwa tidak dilakukannya sosialisasi tentang standar yang harus diketahui dalam pelayanan radiologi. Standar yang berlaku dalam pelayanan hanya ada didalam buku SPM yang juga tidak diketahui oleh semua petugas. Pimpinan rumah sakit yang menyatakan butuh waktu lama dalam mensosilisasikan SPM menunjukkan bahwa rendahnya kesadaran pimpinan bahwa dalam menjalankan pelayanannya setiap petugas harus 
mengetahui dan memahami standar yang berlaku. Hal ini merupakan kegagalan pimpinan dalam menerapkan kebijakan SPM, sehingga tujuan pencapaian target indikator SPM tidak berjalan dengan baik. Pedoman pelayanan unit radiologi yang belum tersedia berdasarkan SOP merupakan salah satu kendala bagi manajemen RSUD dalam upaya tercapainya target pada indikator kebijakan SPM.

Hasil penelitian Ridwan (2017) menjelaskan bahwa Standar Operasi dan Prosedur (SOP) SPM pada RSUD telah dibuat dan dilaksanakan, namun belum tersosialisasikan kepada seluruh pegawai RSUD Undata. ${ }^{12}$ Sejalan dengan hasil penelitian yang dilakukan oleh Kuzairi (2017) menyatakan bahwa terjadi hubungan yang tidak harmonis antara pihak struktural dan fungsional. Hal ini dikarenakan oleh kurangnya komunikasi antar kedua pihak tersebut sehingga membuat pihak fungsional enggan menceritakan permasalahan yang dihadapi dalam pemberian pelayanan kesehatan dan dapat mempengaruhi mutu pelayanan menjadi kurang optimal dan pencapaian implementasi kebijakan SPM RS menjadi rendah. ${ }^{9}$

Proses komunikasi efektif diperlukan dalam kerangka pelaksanaan kebijakan. Pimpinan harus mengkomunikasikan kebijakan yang akan dilaksanakan kepada bidang yang bertanggung jawab agar dapat memahami maksud dan tujuan kebijakan.

\section{b. Disposisi/ Sikap}

Hasil penelitian menunjukkan bahwa petugas memiliki sikap yang mau memberikan pelayanan yang baik yang sesuai dengan SPM dengan pertimbangan membantu rumah sakit untuk memberikan pelayanan terbaik, namun terdapat beberapa kendala yang dihadapi, diantaranya dikarenakan pelaksana ekspertisi (dokter spesialis radiologi) hanya terjadwal hadir di RSUD pada hari senin dan kamis sehingga pelayanan tidak berjalan secara optimal. Kurangnya pemahaman, tenaga, dan ketersediaan fasilitas, serta keinginan dan kemauan pelaksana dalam menjalankan tugas yang sesuai dengan aturan menjadi salah satu kendala lainnya bagi pelaksana RSUD dalam melaksanakan pelayanan yang sesuai dengan SPM.
Hasil penelitian Ridwan (2017) menyatakankan bahwa salah satu indikator yang mempengaruhi implementasi kebijakan adalah sikap dan perilaku implementor. Jika implementor setuju dengan bagianbagian isi dari kebijakan, maka mereka akan melaksanakan dengan senang hati, tetapi jika pandangan mereka berbeda dengan pembuat kebijakan, maka proses implementasi akan mengalami banyak masalah. ${ }^{12}$

Sikap (disposisi) yang kuat bagi pelaksana yang memiliki kapasitas dalam melaksanakan program, maka komponen pelaksana program perlu sepenuh hati dan memiliki komitmen dalam melaksanakan fungsinya sehingga akan menghasilkan pandangan seimbang bahwa program dilaksanakan untuk pengembangan diri ke arah yang lebih baik.

\section{c. Struktur Birokrasi}

Pelaksanaan tanggung jawab Standar Pelayanan Minimal (SPM) yang diserahkan kepada ketua komite mutu merupakan bagian dari struktur organisasi yang harus diemban dan dilaksanakan sebaik-baiknya. Adanya anggaran, fasilitas dan telah dilaksanakannya suatu koordinasi dengan pihak ketiga untuk menjalankan tugas pelaksanaan pengukuran SPM khususnya unit radiologi merupakan bentuk dari telah dijalankannya tugas dan tanggung jawab yang diberikan kepada ketua komite mutu.

Sesuai dengan hasil penelitian Kuzairi (2017) menyatakankan bahwa struktur birokrasi yang kondusif dengan adanya koordinasi dari berbagai pihak ini dapat mempengaruhi pencapaian implementasi kebijakan SPM RS di rumah sakit ini. ${ }^{9}$

\section{Komponen Output}

Berdasarkan hasil pengamatan dilapangan ditemukan bahwa pada indikator SPM masih terdapat berbagai indikator yang targetnya belum tercapai, seperti waktu tunggu hasil pelayanan foto torak yang membutuhkan waktu 2-5 hari untuk mendapatkan hasil ekspertisi dari dokter spesialis radiologi, sedangkan ketentuan pada Peraturan Walikota Padang nomor 39 tahun 2014 menyatakan bahwa waktu tunggu hasil pelayanan thorax foto yaitu maksimum 3 jam. hal ini terjadi karena dokter spesialis radiologi merupakan 
dokter yang masih bersifat referal (tidak tetap) yang jam kerjanya terjadwal hanya pada hari selasa dan kamis. $^{5}$

Dokter yang bertanggung jawab sebagai pelaksana ekspertisi hasil pemeriksaaan rontgen telah sesuai dengan ketentuan yang ditetapkan pada Peraturan Walikota Padang nomor 39 tahun 2014, yaitu $100 \%$ dokter spesialis radiologi. ${ }^{5}$

Kejadian kegagalan pelayanan rontgen yang melebihi dari $2 \%$ kerusakan foto tidak dapat dibaca merupakan salah satu gambaran dari kurangnya efektifitas dan efisiensi dari pelaksana dalam menjalankan pelayanan rontgen, dikarenakan berdasarkan standar pada Peraturan Walikota Padang nomor 39 tahun 2014 menjelaskan bahwa kerusakan foto dalam 1 (satu) bulan tidak boleh melebihi $2 \%{ }^{5}$

Kepuasan pelanggan yang hanya $62 \%$ pasien merasa puas terhadap pelayanan unit radiologi menjelaskan bahwa pelaksana program perlu untuk meningkatkan kinerja dalam memberikan pelayanan terbaik kepada pasien sehingga dapat mewujudkan rasa nyaman dan aman bagi pasien pada saat merujuk ke unit radiologi. Apabila pelaksanaan pelayanan telah dilaksanakan dengan baik, maka hal tersebut dapat meningkatkan kredibilitas pelyanan unit radiologi, sehingga Peraturan Walikota Padang nomor 39 tahun 2014 terkait kepuasan pelanggan unit radiologi dapat melebihi $80 \%{ }^{5}$

Hasil penelitian Rahmat (2014) menjelaskan bahwa adanya rasa ingin meningkatkan pelayanan di rumah sakit merupakan bentuk dari kepedulian penerapan SPM bidang kesehatan. Pihak RSUD telah memahami bahwa tujuan pelayanan kesehatan adalah tercapainya derajat masyarakat yang memuaskan harapan dan kebutuhan derajat masyarakat (consumer satisfaction), melalui pelayanan yang efektif oleh pemberi pelayanan yang memuaskan harapan dan kebutuhan pemberi pelayanan (provider satisfaction), serta pada institusi pelayanan yang diselenggarakan secara efisien (institucional safisfaction). ${ }^{13}$

Keberhasilan suatu program kesehatan, khususnya program pelaksanaan pengukuran SPM antara lain tergantung pada komunikasi informasi yang akurat dan komitmen untuk mempertahankan sumber daya dalam rangka mendukung efektifitas program. ${ }^{14}$

\section{SIMPULAN}

Kebijakan Standar Pelayanan Minimal (SPM) rumah sakit khususnya unit radiologi tersedia berdasarkan Peraturan Walikota Padang nomor 39 tahun 2014 tentang Standar Pelayanan Minimal RSUD $X$ Padang. ${ }^{5}$ Pada indikator SPM yang terdiri dari empat target capaian SPM unit radiologi, RSUD $X$ Padang belum dapat memenuhi capaian target yang dibutuhkan, diantaranya waktu tunggu foto thorak yang lebih dari 3 jam, kejadian kegagalan pelayananan rontgen yang masih mengalami kerusakan lebih dari $2 \%$. Pasien yang belum puas terhadap pelayanan yang diberikan dikarenakan salah satunya akibat dokter yang tidak standby sehingga butuh waktu 2-5 hari untuk mendapatkan hasil foto rontgen.

\section{SARAN}

Pihak manajemen diharapkan untuk melaksanakan sosialisasi secara rutin berkaitan dengan pemahaman pelaksana terhadap SPM, merencanakan perekrutan dokter spesialis agar proses pelayanan unit radioligi berjalan dengan lancar, melaksanakan pelatihan secara rutin untuk meningkatkan kemampuan pelaksana dalam menjalankan tugasnya,

\section{UCAPAN TERIMAKASIH}

Terima kasih atas segala bentuk bantuan yang telah diberikan oleh pihak RSUD X Padang dan pihak terkait yang sudah meluangkan waktu selama proses penelitian ini berlangsung.

\section{DAFTAR PUSTAKA}

1. Brigham E, Houston J. Manajemen keuangan buku. Edisi Ke-8. Jakarta: Erlangga; 2001.

2. endradita $m$, galih. panduan pelayanan Radiologi. 2017 [diakses 14 Mei 2018]. Tersedia dari: http:// www.panduindonesia.co.id

3. Azwar. Menjaga mutu pelayanan kesehatan Aplikasi Prinsip Lingkaran Pemecahan Masalah. Jakarta: Pustaka Sinar Harapan ; 2006.

4. Departemen Kesehatan RI (Depkes RI). Keputusan Menteri Kesehatan Republik Indonesia nomor 129. standar pelayanan minimal rumah sakit. Jakarta: Depkes RI; 2008. 
5. Peraturan Walikota Padang Nomor 39. Standar pelayanan minimal rumah sakit umum daerah $\mathrm{dr}$. Rasidin. Padang ; 2014.

6. Mulyadi D. Studi kebijakan publik dan pelayanan publik konsep dan aplikasi proses kebijakan publik dan pelayanan publik. Bandung: Alfabeta; 2014.hlm.86 -7.

7. Depkes RI. Keputusan menteri kesehatan nomor 1014. standar pelayanan radiologi diagnostik disarana pelayanan kesehatan. Jakarta: Depkes $\mathrm{RI} ; 2008$.

8. RSUD Dr. Rasidin. Laporan tahunan RSUD dr. Rasidin Padang. Padang: RSUD Dr. Rasidin; 2017.

9. Kuzairi U. Implementasi standar pelayanan minimal (SPM) pada pelayanan publik bidang pelayanan kesehatan (studi kasus pada rumah sakit umum dr.H. Koesnadi Bondowoso) [disertasi]. Program
Doktor Imu Administrasi Fakultas IImu Sosial dan IImu Politik Universitas Jember. Jember; 2017.

10. Saputra DR. Implementasi standar pelayanan minimal bidang kesehatan di RSUD Kota Baubau [tesis]. .Jurnal IImu Pemerintahan. 2014;2 Juni

11. Subarsono. Analisis kebijakan publik. Yogyakarta: Pustaka Pelajar; 2008.hlm.129 -30.

12. Ridwan B. Implementasi kebijakan standar pelayanan minimal di RSUD Undata Provinsi Sulawesi Tengah. e Jurnal Katalogis. Desember 2017;5(12): 108-17.

13. Rahmat. Implementasi Standar Pelayanan Minimal Bidang kesehatan di RSUD Kota Baubau. Program Studi Magister Ilmu Pemerintahan Universitas Muhammadiyah. Yogyakarta. Tesis ; 2014.

14. Frieden T. Six components necessary for effective public health program implementation. American Journal of Public Health. 2014;104(1):17-22. 